\title{
Assessing Mental Illness Stigma: A Complex Issue
}

\author{
Stefania Mannarini ${ }^{1,2 *}$ and Alessandro Rossi ${ }^{1,2}$ \\ ${ }^{1}$ Interdepartmental Center for Family Research, University of Padova, Padova, Italy, ${ }^{2}$ Section of Applied Psychology, \\ Department of Philosophy, Sociology, Education, and Applied Psychology, University of Padova, Padova, Italy
}

Keywords: mental illness stigma, mental illness, stigma, mental health stigma, assessment

To date, stigma toward individuals with Mental Illness (MI) is a severe social problem as well as a heavy burden for affected people (Corrigan, 2005; Oexle and Corrigan, 2018). While public knowledge about physical diseases is usually seen as beneficial, knowledge about MI is often disregarded (Angermeyer and Dietrich, 2006). As a consequence, many persons suffering from common mental disorders may not receive appropriate (therapeutic) social support due to the community's lack of awareness (Jorm, 2000; Ratti et al., 2017). Indeed, although an increase in the number of individuals seeking psychological support has been registered worldwide (Fang et al., 2011; Picco et al., 2016), a significant number of people still avoid asking for help. Possible causes of this mismatch are the tendency of some persons to think that MI difficulties will resolve spontaneously (Sareen et al., 2007; Wilson and Deane, 2012) and/or their reluctance to bear the costs of therapies (Vogel and Wester, 2003; Castelnuovo et al., 2016) and/or they might even consider the possible long-term ineffectiveness of certain approaches (Harding and Zahniser, 1994; Parker and Fletcher, 2007; Beutler, 2009; Barlow et al., 2013; Lilienfeld et al., 2014; Sorgente et al., 2017; Jackson et al., 2018). Moreover, people avoid seeking professional help due to the fear of disclosing a diagnosis which involves stigma associated with MI (Hinshaw, 2007; Mannarini and Boffo, 2015).

Indeed, although the knowledge of MI has been improved (Kendler and Prescott, 2006; Schnyder et al., 2018), scientific literature showed that people usually perceive individuals with MI as dangerous (Angermeyer and Matschinger, 2005). Walker and Read (2002) showed that people's dominant impression on $\mathrm{MI}$ is that it leads to unpredictable behaviors and loss of control. Scientific literature demonstrated otherwise that the relationship between the majority of psychiatric disorders and violent behaviors does not exist, showing that attitudes toward people with MI are in most cases related to a biased prejudice and/or stereotype (Walker and Read, 2002; Angermeyer and Matschinger, 2005; McGinty et al., 2018). People with MI are often subjected to discriminative and stigmatizing behaviors (Wahl, 1999; Hinshaw, 2007) in the social context (Corrigan et al., 2012), inside their families and among friends (Wahl, 1999; Hinshaw, 2007). This constant exposure to stigmatizing attitudes has numerous negative effects, such as: lower quality of life, critical impediments in seeking professional help, treatment discontinuity, and higher dropout rates (Sirey et al., 2001; Hinshaw, 2007; Livingston and Boyd, 2010).

In addition, stigma toward people with MI is both a cross-diagnostic (Mannarini and Boffo, 2015) and a cross-cultural phenomenon (Read and Harré, 2001; Jorm and Griffiths, 2008; Abdullah and Brown, 2011; Mannarini et al., 2017, 2018). A study conducted in three countries (Germany, Russia, and Mongolia), involving two mental disorders (depression and schizophrenia), revealed comparable overall results regardless of strong differences in cultural backgrounds. At the same time, findings also suggested differences at the level of specific indicators, namely in the relation between mental disorders, etiological causal beliefs, and social distance toward people with MI (Dietrich et al., 2004). More in detail, people were more likely to attribute the etiology of both pathologies to psychological causes instead of biological ones. It was also found that the endorsement of biological causes as primary beliefs of mental disorders was associated with a

Assessing Mental Illness Stigma: A

Complex Issue.

Front. Psychol. 9:2722.

doi: 10.3389/fpsyg.2018.02722 
greater social distance. On this subject, in several samples of Italian participants, Magliano et al. (2004) showed that the main cause of social distance and stigmatization was the diagnosis attributed to the patient. Schomerus et al. (2011) examined 17 studies, representative of several populations, regarding stigma toward people with MI. Results suggested that there is a significant effect linked to the cultural context influencing how people perceive mental disorders and stigmatize individuals with MI: they showed that these differences concerned variables such as blaming, dangerousness, emotional reactions, and desire of distance (Schomerus et al., 2006). The significant effect of cultural characteristics on the perception of specific variables regarding MI individuals was also confirmed by other studies (Abdullah and Brown, 2011; Angermeyer et al., 2011; Schomerus et al., 2011). According to these results, Pescosolido et al. (2010) found that causal beliefs, attitudes toward people with MI and cultural context were also associated. Furthermore, they found a positive correlation between the tendency to give a biological explanation of mental disorders and a higher recommendation of therapeutic treatment(s) (Pescosolido et al., 2010). Finally, Mannarini and colleagues extended previous findings by studying etiological beliefs in relation to perceived dangerousness, social closeness, and avoidance toward people with MI in Italian and Israeli students. Using a Latent Class approach they found an interaction effect of culture on the latent structure of variables able to describe attitudes toward MI (Mannarini et al., 2016, 2017, 2018).

Etiological beliefs of mental disorders have been extensively studied from this perspective. Results revealed that-regardless of cross-cultural context-the most recurrently indicated types of causes were both biological and psychosocial factors (Jorm, 2000; Sears et al., 2011). In an attempt to achieve representative results, the relationship between etiological beliefs and discriminating attitudes toward MI people has driven to a long-lasting debate in the field, leading to an encouraging research production worldwide (Read and Harré, 2001; Walker and Read, 2002; Rüsch et al., 2005; Corrigan, 2016). Indeed, the cause to which the MI condition is attributed (psycho-sociological vs. biogenetic) has been considered to be one of the main factors underlying the stigmatizing processes (Feldman and Crandall, 2007). Consequently, etiological beliefs have been used as a promotional trigger to overcome stigma in several public health programs aimed to reduce discrimination toward people with MI (Corrigan et al., 2018; Morgan et al., 2018). The promotion of bio-genetic approach to etiological beliefs of MI has been considered as the most promising approach to reduce stigma; this is due to the higher association between this specific belief and perception of onset/offset controllability (Larkings and Brown, 2018). By promoting a medical approach, these campaigns strongly emphasized the endorsement of biogenetic causal models of MI by explicitly portraying mental disorders as medical conditions that should be treated with medical treatments: i.e., the "mental illness is an illness like any other" (Corrigan, 2000; Read et al., 2006; Schomerus et al., 2012). The attribution theory framework could explain this perspective by postulating that specific emotional, attitudinal and behavioral responses toward a person are generated by causal attributions over his/her behaviors (Weiner, 1995). Along this line, when causes of mental health problems are attributed to external factors, outside of individual control, such as biological and/or genetic causes, the reactions toward persons with MI should be less negative. Conversely, if the cause of mental disorders is attributed to an individual's character that is considered an internal cause, people would be less willing to interact with him/her (Corrigan, 2000).Thus, campaigns aimed to reduce ascriptions of responsibility and guilt toward the affected persons, since such causes are beyond the individual control. Therefore, by aiming to change the perception that people with mental disorders should be blamed for their troubles, they may lead to lower rejection attitudes in social contexts (Corrigan, 2000).

However, despite these theoretically-based premises, these campaigns sponsoring a bio-genetic cause of mental disorders did not produce the desired effect in reducing stigmatizing attitudes. Indeed, the result of these social interventions was a mixed and contradictory pattern of both negative and positive emotions and cognitions, such as: higher levels of negative stigma as well as a higher endorsement of professional MI treatments and MI scientific literacy (Angermeyer et al., 2011; Kvaale et al., 2013). Indeed, these strategies didn't consider that bio-genetic causal beliefs are associated to the perception that people with MI are considered dangerous, uncontrollable, and antisocial (Read and Law, 1999). Proclaiming a "wrong" brain functioning as a cause of mental disorders strongly increase the dangerousness perception of such individuals, due to the possible unawareness of their behaviors (Read and Harré, 2001; Dietrich et al., 2004; Angermeyer and Matschinger, 2005). These results suggested that encouraging biological models as explanation of mental disorders is not useful to reduce stigmatization as well as social distance (Walker and Read, 2002; Angermeyer et al., 2011). In order to decrease social isolation of people with MI, campaigns against MI stigma should provide more attention to deepen the differences in opinions and beliefs over different disorders. This way, more adequate educational programs and appropriate clinical interventions could be developed (Corrigan et al., 2001; Angermeyer and Dietrich, 2006; Gatta et al., 2017) as well as the affective and public rights of the patients (Magliano et al., 2004). Thus, a precise and in-deep understanding of prejudice as well as stereotypes toward mental health disorders is fundamental to improve the effectiveness of mental health campaigns designed to reduce MI stigma (Monteith and Pettit, 2011).

However, it has to be highlighted that research on MI stigma showed some limitations. First of all, this subject has been studied mainly focusing on studies with self-report measures (Link et al., 2004). Questionnaires are aimed to assess opinions and attitudes about behaviors of a person with mental disorders, about his/her relationships and the etiology of MI (Luty et al., 2006; Mannarini and Boffo, 2013). However, since certain opinions and attitudes can be considered discriminatory, consequently it is likely that respondents' answers are influenced by social desirability concerns (Stier and Hinshaw, 2007). Along these lines, research on MI stigma could progress by focusing on the role of implicit processes and developing measures able to assess implicit cognitions, attitudes, and causal beliefs expressed beyond the individual's conscious control (Mannarini and Boffo, 2014). Considering that both controlled deliberate responses 
and automatic implicit responses are involved in stigmatization processes (Dovidio et al., 1997; Reeder and Pryor, 2008), indirect measurement procedures, such as the Implicit Association Test (IAT) (Greenwald et al., 1998) or other speeded reaction-time tasks, could bypass these issues.

In addition, research on this topic, as well as the heterogeneity of findings, showed that studies on MI stigma usually focus only on one (or few) factor(s) composing this multi-structured construct. Moreover, these studies did not consider more than one mental disorder per time, in particular: schizophrenia, depression, and addiction disorders (Room, 2005; Peluso and Blay, 2009; Pescosolido et al., 2010; Schomerus et al., 2011). Otherwise, the measurements of MI stigma are conducted by referring to $\mathrm{MI}$ as a universal category including heterogeneous and different diagnostic categories, thus leading to a loss of focus over each mental disorder specificities (Angermeyer and Matschinger, 2005; Jorm et al., 2006; Mannarini and Boffo, 2015). Along these lines, a vignette approach could overcome this issue. According to DSM-V diagnostic criteria (American Psychiatric Association, 2013), a vignette is a brief sketch and/or an unlabeled story representing problems and symptoms of a specific mental disorder (Angermeyer and Matschinger, 2005; Jorm et al., 2006). In the vignette procedure proposed by Mannarini and Boffo (2015) any specific mental disorder is mentioned in

\section{REFERENCES}

Abdullah, T., and Brown, T. L. (2011). Mental illness stigma and ethnocultural beliefs, values, and norms: an integrative review. Clin. Psychol. Rev. 31, 934-948. doi: 10.1016/j.cpr.2011.05.003

American Psychiatric Association (2013). Diagnostic and Statistical Manual of Mental Disorders. Washington, DC: American Psychiatric Association.

Angermeyer, M. C., and Dietrich, S. (2006). Public beliefs about and attitudes towards people with mental illness: a review of population studies. Acta Psychiatr. Scand. 113, 163-179. doi: 10.1111/j.1600-0447.2005.00699.x

Angermeyer, M. C., Holzinger, A., Carta, M. G., and Schomerus, G. (2011). Biogenetic explanations and public acceptance of mental illness: systematic review of population studies. Br J Psychiatry 199, 367-372. doi: 10.1192/bjp.bp.110.085563

Angermeyer, M. C., and Matschinger, H. (2005). Causal beliefs and attitudes to people with schizophrenia. Trend analysis based on data from two population surveys in Germany. Br J. Psychiatry 186, 331-334. doi: 10.1192/bjp.186.4.331

Barlow, D. H., Bullis, J. R., Comer, J. S., and Ametaj, A. A. (2013). Evidence-based psychological treatments: an update and a way forward. Ann. Rev. Clin. Psychol. 9, 1-27. doi: 10.1146/annurev-clinpsy-050212-185629

Beutler, L. E. (2009). Making science matter in clinical practice: redefining psychotherapy. Clin. Psychol. Sci. Prac. 16, 301-317. doi: 10.1111/j.1468-2850.2009.01168.x

Castelnuovo, G., Pietrabissa, G., Cattivelli, R., Manzoni, G. M., and Molinari, E. (2016). Not only clinical efficacy in psychological treatments: clinical psychology must promote cost-benefit, cost-effectiveness and cost-utility analysis. Front. Psychol. 7:563. doi: 10.3389/fpsyg.2016.00563

Corrigan, P. W. (2000). Mental health stigma as social attribution: implications for research methods and attitude change. Clin. Psychol. Sci. Prac. 7, 48-67. doi: 10.1093/clipsy.7.1.48

Corrigan, P. W. (2005). On the Stigma of Mental Illness: Practical Strategies for Research and Social Change. Washington, DC: American Psychological Association.

Corrigan, P. W. (2016). Resolving mental illness stigma: should we seek normalcy or solidarity? Br. J. Psychiatry 208, 314-315. doi: 10.1192/bjp.bp.115.169664 any part of the text, and participants were asked to evaluate several variables, such as: the etiology of the person's problems depicted in the vignette as well as possible treatments, the degree of dangerousness and the desire of social distance from that person.

In conclusion, considering the abovementioned background and the myriad of findings pointed out by the scientific research, it seems that assessing stigma is a very complex issue. Indeed, it involves complex evaluation procedures able to define structures of interactive variables, such as etiological beliefs, attitudes, prejudices, personal, and social problems, both toward mentally ill persons and in the mental disorders' perceiver, while taking into account the role of different cultures. A key role is also played by treatments and their relations with causal beliefs and with other variables. Furthermore, and of fundamental importance in this context is the distinction of different mental disorders, such as schizophrenia, depression, and addiction, which should be studied separately to highlight the specificity of their relations with stigma.

\section{AUTHOR CONTRIBUTIONS}

SM conceived the manuscript. SM and AR wrote the manuscript, critically revised it, and approved the final version.

Corrigan, P. W., Morris, S. B., Michaels, P. J., Rafacz, J. D., and Rusch, N. (2012). Challenging the public stigma of mental illness: a meta-analysis of outcome studies. Psychiatr. Serv. 63, 963-973. doi: 10.1176/appi.ps.201100529

Corrigan, P. W., River, L. P., Lundin, R. K., Penn, D. L., UphoffWasowski, K., Campion, J., et al. (2001). Three strategies for changing attributions about severe mental illness. Schizophr. Bull. 27, 187-195. doi: 10.1093/oxfordjournals.schbul.a006865

Corrigan, P. W., Rüsch, N., and Scior, K. (2018). Adapting disclosure programs to reduce the stigma of mental illness. Psychiatr. Serv. 69, 826-828. doi: 10.1176/appi.ps.201700478

Dietrich, S., Beck, M., Bujantugs, B., Kenzine, D., Matschinger, H., and Angermeyer, M. C. (2004). The relationship between public causal beliefs and social distance toward mentally ill people. Austr. N Z J. Psychiatry 38, 348-354. doi: 10.1080/j.1440-1614.2004.01363.x

Dovidio, J., Kawakami, K., Johnson, C., Johnson, B., and Howard, A. (1997). On the nature of prejudice: automatic and controlled processes. J. Exp. Soc. Psychol. 33, 510-540. doi: 10.1006/jesp.1997.1331

Fang, K., Pieterse, A. L., Friedlander, M., and Cao, J. (2011). Assessing the psychometric properties of the attitudes toward seeking professional psychological help scale-short form in mainland China. Int. J. Adv. Counsel. 33, 309-321. doi: 10.1007/s10447-011-9137-1

Feldman, D. B., and Crandall, C. S. (2007). Dimensions of mental illness stigma: what about mental illness causes social rejection? J. Soc. Clin. Psychol. 26, 137-154. doi: 10.1521/jscp.2007.26.2.137

Gatta, M., Balottin, L., Mannarini, S., Chesani, G., Del Col, L., Spoto, A., et al. (2017). Familial factors relating to alexithymic traits in adolescents with psychiatric disorders. Clin. Psychol. 21, 252-262. doi: 10.1111/cp.12098

Greenwald, A. G., McGhee, D. E., and Schwartz, J. L. K. (1998). Measuring individual differences in implicit cognition: the implicit association test. J. Pers. Soc. Psychol. 74, 1464-1480. doi: 10.1037/0022-3514.74.6.1464

Harding, C. M., and Zahniser, J. H. (1994). Empirical correction of seven myths about schizophrenia with implications for treatment. Acta Psychiatr. Scand. 90, 140-146. doi: 10.1111/j.1600-0447.1994.tb05903.x

Hinshaw, S. P. (2007). The Mark of Shame: Stigma of Mental Illness and An Agenda for Change. New York, NY: Oxford University Press. 
Jackson, J. B., Pietrabissa, G., Rossi, A., Manzoni, G. M., and Castelnuovo, G. (2018). Brief strategic therapy and cognitive behavioral therapy for women with binge eating disorder and comorbid obesity: a randomized clinical trial oneyear follow-up. J. Consul. Clin. Psychol. 86, 688-701. doi: 10.1037/ccp0000313

Jorm, A. F. (2000). Mental health literacy. Public knowledge and beliefs about mental disorders. Br. J. Psychiatry 177, 396-401. doi: 10.1192/bjp.177.5.396

Jorm, A. F., Christensen, H., and Griffiths, K. M. (2006). The public's ability to recognize mental disorders and their beliefs about treatments: changes in Australia over 8 years. Aus. N. Z. J. Psychiatry 40, 36-41. doi: $10.1111 / j .1440-1614.2006 .01738 . x$

Jorm, A. F., and Griffiths, K. M. (2008). The public's stigmatizing attitudes towards people with mental disorders: how important are biomedical conceptualizations? Acta Psychiatr. Scand. 118, 315-321. doi: 10.1111/j.1600-0447.2008.01251.x

Kendler, K. S., and Prescott, C. A. (2006). Genes, Environment and Psychopathology: Understanding the Causes of Psychiatric and Substance Use Disorders. New York, NY: Guilford Press.

Kvaale, E. P., Haslam, N., and Gottdiener, W. H. (2013). The 'side effects' of medicalization: A meta-analytic review of how biogenetic explanations affect stigma. Clin. Psychol. Rev. 33, 782-794. doi: 10.1016/j.cpr.2013.06.002

Larkings, J. S., and Brown, P. M. (2018). Do biogenetic causal beliefs reduce mental illness stigma in people with mental illness and in mental health professionals? A systematic review. Int. J. Ment. Health Nurs. 27, 928-941. doi: $10.1111 /$ inm. 12390

Lilienfeld, S. O., Ritschel, L. A., Lynn, S. J., Cautin, R. L., and Latzman, R. D. (2014). Why ineffective psychotherapies appear to work: a taxonomy of causes of spurious therapeutic effectiveness. Pers. Psychol. Sci. 9, 355-387. doi: $10.1177 / 1745691614535216$

Link, B. G., Yang, L. H., Phelan, J. C., and Collins, P. Y. (2004). Measuring mental illness stigma. Schizophr. Bull. 30, 511-541. doi: 10.1093/oxfordjournals.schbul.a007098

Livingston, J. D., and Boyd, J. E. (2010). Correlates and consequences of internalized stigma for people living with mental illness: a systematic review and meta-analysis. Soc. Sci. Med. 71, 2150-2161. doi: $10.1016 /$ j.socscimed.2010.09.030

Luty, J., Fekadu, D., Umoh, O., and Gallagher, J. (2006). Validation of a short instrument to measure stigmatized attitudes towards mental illness. Psychiatrist 30, 257-260. doi: 10.1192/pb.30.7.257

Magliano, L., Fiorillo, A., De Rosa, C., Malangone, C., and Maj, M. (2004). Beliefs about schizophrenia in Italy: a comparative nationwide survey of the general public, mental health professionals, and patients' relatives. Can. J. Psychiatry 49, 322-330. doi: 10.1177/070674370404900508

Mannarini, S., Balottin, L., Toldo, I., and Gatta, M. (2016). Alexithymia and psychosocial problems among Italian preadolescents. A latent class analysis approach. Scand. J. Psychol. 57, 473-481. doi: 10.1111/sjop.12300

Mannarini, S., and Boffo, M. (2013). Assessing mental disorder causal beliefs: a latent dimension identification. Comm. Mental Health J. 49, 686-693. doi: 10.1007/s10597-012-9581-3

Mannarini, S., and Boffo, M. (2014). An implicit measure of associations with mental illness versus physical illness: response latency decomposition and stimuli differential functioning in relation to IAT order of associative conditions and accuracy. PLoS ONE 9:e101911. doi: 10.1371/journal.pone.0101911

Mannarini, S., and Boffo, M. (2015). Anxiety, bulimia, drug and alcohol addiction, depression, and schizophrenia: what do you think about their aetiology, dangerousness, social distance, and treatment? A latent class analysis approach. Soc. Psychiatry Psychiatr. Epidemiol. 50, 27-37. doi: 10.1007/s00127-014-0925-x

Mannarini, S., Boffo, M., Rossi, A., and Balottin, L. (2018). Etiological beliefs, treatments, stigmatizing attitudes towards schizophrenia. What do Italians and Israeli think? Front. Psychol. 8:2289. doi: 10.3389/fpsyg.2017.02289

Mannarini, S., Reikher, A., Shani, S., and Shani- Zinovich, I. (2017). The role of secure attachment, empathic self-efficacy and stress perception in causal beliefs related to mental illness. A cross-cultural study: Italy versus Israel. Psychol. Res. Behav. Manag. 10, 313-321. doi: 10.2147/PRBM.S138683

McGinty, E. E., Goldman, H. H., Pescosolido, B. A., and Barry, C. L. (2018). Communicating about mental illness and violence: balancing stigma and increased support for services. J. Health Polit. Policy Law 43, 185-228. doi: $10.1215 / 03616878-4303507$
Monteith, L. L., and Pettit, J. W. (2011). Implicit and explicit stigmatizing attitudes and stereotypes about depression. J. Soc. Clin. Psychol. 30, 484-505. doi: 10.1521/jscp.2011.30.5.484

Morgan, A. J., Reavley, N. J., Ross, A., San Too, L., and Jorm, A. F. (2018). Interventions to reduce stigma towards people with severe mental illness: systematic review and meta-analysis. J. Psychiatric Res. 103, 120-133. doi: 10.1016/j.jpsychires.2018.05.017

Oexle, N., and Corrigan, P. W. (2018). Understanding mental illness stigma toward persons with multiple stigmatized conditions: implications of intersectionality theory. Psychiatric Serv. 69, 587-589. doi: 10.1176/appi.ps.201700312

Parker, G., and Fletcher, K. (2007). Treating depression with the evidence-based psychotherapies: a critique of the evidence. Acta Psychiatr. Scand. 115, 352-359. doi: 10.1111/j.1600-0447.2007.01007.x

Peluso, E. T. P., and Blay, S. L. (2009). Public stigma in relation to individuals with depression. J. Affect. Disord. 115, 201-206. doi: 10.1016/j.jad.2008.08.013

Pescosolido, B. A., Martin, J. K., Long, J. S., Medina, T. R., Phelan, J. C., and Link, B. G. (2010). "A disease like any other"? A decade of change in public reactions to schizophrenia, depression, and alcohol dependence. Am. J. Psychiatry 167, 1321-1330. doi: 10.1176/appi.ajp.2010.09121743

Picco, L., Abdin, E., Chong, S. A., Pang, S., Shafie, S., Chua, B. Y., et al. (2016). Attitudes toward seeking professional psychological help: factor structure and socio-demographic predictors. Front Psychol 7:547. doi: $10.3389 /$ fpsyg.2016.00547

Ratti, M. M., Rossi, A., Delli Zotti, G. B., Sarno, L., and Spotti, D. (2017). Social support, psychological distress and depression in hemodialysis patients. Psicologia della Salute 1, 112-122. doi: 10.3280/PDS2017-001006

Read, J., and Harré, N. (2001). The role of biological and genetic causal beliefs in the stigmatisation of "mental patients". J. Ment Health 10, 223-235. doi: $10.1080 / 09638230123129$

Read, J., Haslam, N., Sayce, L., and Davies, E. (2006). Prejudice and schizophrenia: a review of the "mental illness is an illness like any other" approach. Acta Psychiatr. Scand. 114, 303-318. doi: 10.1111/j.1600-0447.2006.00824.x

Read, J., and Law, A. (1999). The relationship of causal beliefs and contact with users of mental health services to attitudes to the "mentally ill". Int. J. Soc. Psychiatry 45, 216-229. doi: 10.1177/002076409904500309

Reeder, G. D., and Pryor, J. B. (2008). Dual psychological processes underlying public stigma and the implications for reducing stigma. Mens Sana Monogr. 6, 175-186. doi: 10.4103/0973-1229.36546

Room, R. (2005). Stigma social inequality and alcohol and drug use. Drug Alcohol Rev. 24, 143-155. doi: 10.1080/09595230500102434

Rüsch, N., Angermeyer, M. C., and Corrigan, P. W. (2005). Mental illness stigma: concepts, consequences, and initiatives to reduce stigma. Eur. Psychiatry 20, 529-539. doi: 10.1016/j.eurpsy.2005.04.004

Sareen, J., Jagdeo, A., Cox, B. J., Clara, I., tenHave, M., Belik, S., et al. (2007). Perceived barriers to mental health service utilization in the United States, Ontario, and the Netherlands. Psychiatr. Serv. 58, 357-364. doi: 10.1176/ps.2007.58.3.357

Schnyder, N., Michel, C., Panczak, R., Ochsenbein, S., Schimmelmann, B. G., and Schultze-Lutter, F. (2018). The interplay of etiological knowledge and mental illness stigma on healthcare utilisation in the community: a structural equation model. Eur. Psychiatry 51, 48-56. doi: 10.1016/j.eurpsy.2017.12.027

Schomerus, G., Borsche, J. H., Matschinger, H., and Angermeyer, M. C. (2006). Public knowledge about causes and treatment for schizophrenia. J. Nerv. Ment. Dis. 194, 622-624. doi: 10.1097/01.nmd.0000231428.98039.6c

Schomerus, G., Lucht, M., Holzinger, A., Matschinger, H., Carta, M. G., and Angermeyer, M. C. (2011). The stigma of alcohol dependence compared with other mental disorders: a review of population studies. Alcohol Alcohol. 46, 105-112. doi: 10.1093/alcalc/agq089

Schomerus, G., Schwahn, C., Holzinger, A., Corrigan, P. W., Grabe, H. J., Carta, M. G., et al. (2012). Evolution of public attitudes about mental illness: a systematic review and metaanalysis. Acta Psychiatr. Scand. 125, 440-452. doi: 10.1111/j.1600-0447.2012.01826.x

Sears, P. M., Pomerantz, A. M., Segrist, D. J., and Rose, P. (2011). Beliefs about the biological (vs. nonbiological) origins of mental illness and the stigmatization of people with mental illness. Am. J. Psychiatr. Rehabil. 14, 109-119. doi: 10.1080/15487768.2011.569665

Sirey, J. A., Bruce, M. L., Alexopoulos, G. S., Perlick, D. A., Raue, P., Friedman, S. J., et al. (2001). Perceived stigma as a predictor of treatment discontinuation in 
young and older outpatients with depression. Am. J. Psychiatry 158, 479-481. doi: 10.1176/appi.ajp.158.3.47

Sorgente, A., Pietrabissa, G., MauroManzoni, G., Re, F., Simpson, S., Perona, S., et al. (2017). Web-based interventions for weight loss or weight loss maintenance in overweight and obese people: a systematic review of systematic reviews. J. Med. Int. Res. 19:6. doi: 10.2196/jmir.6972

Stier, A., and Hinshaw, S. P. (2007). Explicit and implicit stigma against individuals with mental illness. Aust Psychol. 42, 106-117. doi: $10.1080 / 00050060701280599$

Vogel, D. L., and Wester, S. R. (2003). To seek help or not to seek help: the risks of self-disclosure. J. Counsel. Psychol. 50, 351-361. doi: 10.1037/0022-0167.50.3.351

Wahl, O. (1999). Mental Health Consumers' experience of stigma. Schizophr. Bull 25, 467-478. doi: 10.1093/oxfordjournals.schbul.a033394

Walker, I., and Read, J. (2002). The differential effectiveness of psychosocial and biogenetic causal explanations in reducing negative attitudes toward "mental illness". Psychiatry 65, 313-325. doi: 10.1521/psyc.65.4.313.20238
Weiner, B. (1995). Judgments of Responsibility: A Foundation for a Theory of Social Conduct. New York, NY: Guilford Press.

Wilson, C. J., and Deane, F. P. (2012). Brief report: need for autonomy and other perceived barriers relating to adolescents' intentions to seek professional mental health care. J. Adoles. 35, 233-237. doi: 10.1016/j.adolescence.2010.06.011

Conflict of Interest Statement: The authors declare that the research was conducted in the absence of any commercial or financial relationships that could be construed as a potential conflict of interest.

Copyright (๑) 2019 Mannarini and Rossi. This is an open-access article distributed under the terms of the Creative Commons Attribution License (CC BY). The use, distribution or reproduction in other forums is permitted, provided the original author(s) and the copyright owner(s) are credited and that the original publication in this journal is cited, in accordance with accepted academic practice. No use, distribution or reproduction is permitted which does not comply with these terms. 